\title{
WAYANG GOLEK RINGAN PEMANFAATAN LIMBAH SEBAGAI PENGEMBANGAN BONEKA WAYANG GOLEK
}

\author{
Trisno Santoso \\ Program Studi Seni Teater, Fakultas Seni Pertunjukan \\ Institut Seni Indonesia Surakarta \\ JI. Ki Hadjar Dewantara No. 19 Kentingan, Jebres, Surakarta, 57126 \\ Email: trisnopelok@yahoo.com
}

\begin{abstract}
ABSTRAK
Wayang Golek Ménak Sentolo pernah mengalami masa kejayaan, tetapi kini pertunjukan wayang tersebut dapat dikatakan mati. Perlu adanya inovasi di segala hal, penelitian ini menggali dan berinovasi pada penemuan boneka wayang besar tetapi ringan, serta menggunakan bahan utama dari limbah. Rekayasa model pembuatan boneka wayang golek baru, untuk menghindari penebangan kayu. Pembuatan boneka wayang ini mempunyai kebaruan dalam berbagai unsur yaitu; bahan utama, tata busana, tata rias, serta cara menyambung tangan pada boneka Wayang Golek. Pembuatan kepala boneka Wayang Golek memanfaatkan dahan kayu albasiyah, kemudian dikolaborasikan dengan kertas bekas pembungkus semen, dakron, kain perca, dan styrofoam bekas. Metode pencapaian untuk menciptakan boneka merupakan kombinasi antara metode kerja lapangan dengan metode pengamatan, wawancara, studi pustaka, Partisipant Art Reseach Technic (PART), Focus Group Diccuscion (FGD), eksplorasi, dan empiris. Hasil yang dicapai pada eksplorasi pembuatan boneka Wayang Golek dari bahan limbah dapat mengurangi bobot antara $30 \%$ sampai dengan $50 \%$ lebih ringan apabila dibandinglkan dengan bobot boneka wayang dari bahan utama kayu. Sedangkan nilai bahannya dapat dikatakan murah karena memanfaatkan barang-barang limbah.
\end{abstract}

Kata kunci: Wayang Golek Ringan, Bahan Limbah.

\section{ABSTRACT}

Puppet Golek Ménak Sentolo has experienced its glory but now it seems to be dissappeared. There needs to be innovation in everything. This research tries to explore and innovate on the discovery of a large but light doll of wayang utilizing waste material as the main ingredients. It is supposed to avoid logging. The making of this wayang has novelty in various elements namely; the main ingredients, fashion, makeup, and the way to connect the hands of the wayang. The making of Wayang Golek head utilizes albasiyah wood branches, then collaborated with used paper of cement wrapped, dacron, patchwork, and used styrofoam. The achievement method for creating puppets is a combination of fieldwork methods of observation, interviews, literature study, Participatory Art Research Technic (PART), Focus Group Discussion (FGD), exploration, and empirical. The results achieved show that the exploration of puppet making from waste materials can reduce the weight between $30 \%$ to $50 \%$ lighter than the puppets made of wood. While the value of the ingredients is also cheaper because it utilizes waste items.

Keywords: Wayang Golek, light, waste material.

\section{A. Pengantar}

Pertunjukan wayang di Jawa terdapat berbagai jenis, ragam, dan namanya, di antaranya: Wayang Purwa, Wayang Gedhog, Wayang Madya, Wayang Kulit Ménak, Wayang Klithik, Wayang Kancil, Wayang Wahyu, Wayang Dupara, Wayang Sadat, Wayang Golek Ménak, dan lain-lain (Satoto, 2012: 124-139) Di Sentolo, Kabupaten Kulon Progo, Daerah Istimewa
Yogyakarta pernah muncul pertunjukan Wayang Golek Ménak. Wayang Golek ini tidak menggunakan kelér atau layar seperti pada pertunjukan Wayang Kulit. Tinggi panggung yang digunakan untuk memainkan Wayang Golek lebih tinggi apabila dibandingkan dengan tinggi panggung pada pertunjukan Wayang Kulit. Batang pisang atau gedebog yang digunakan untuk menancapkan wayang pada pertunjukan Wayang Kulit setinggi $60 \mathrm{~cm}$, sedangkan pada 


\section{GEEAR Jumal sai isubya}

pertunjukan Wayang Golek setinggi $80 \mathrm{~cm}$. Hal ini, dimaksudkan agar dalang sebagai penggerak wayang tidak menghalangi pandangan penonton yang melihat dari belakang dalang dan apabila dilihat dari depan dalang seolah-olah wayang tidak ada yang menggerakkan (Santoso, 2016:4).

Wayang Golek Ménak Sentolo adalah salah satu bentuk pertunjukan Wayang Golek atau wayang tiga dimensi sebagai hasil produk budaya masyarakat setempat yang ada dan tercipta atas dasar keinginan untuk memenuhi kebutuhan di bidang etik dan estetik pada zamannya. Ketika produk yang berbentuk karya seni pertunjukan seperti Wayang Golek menjadi tidak sesuai lagi dengan tuntutan jamannya, terlindas oleh laju peradaban dan percepatan selera masyarakat akan apresiasi seni, maka bentuk kesenian ini ditantang untuk mengikuti perubahan tersebut. Akan tetapi seniman pendukung Wayang Golek Ménak Sentolo ini sangat sedikit jumlahnya dan kesulitan mengikuti arus jaman. Selama 3 generasi hanya ditemukan ada 4 dalang Wayang Golek Ménak Sentolo yang masih eksis. Widiprayitna adalah dalang dan pengembang pertama Wayang Golek Ménak Sentolo, yang kemudian dilanjutkan oleh Sukarna putranya serta Suparman salah satu pengrawit Widiprayitna yang mempelajari Wayang Golek. Cucu Widiprayitna, yaitu Trisno Santoso, R Yuwono, dan Dewanto Sukistono pada saat ini sedang menekuni Wayang Golek Ménak Sentolo, sedangkan di luar Sentolo juga ditekuni oleh Suharno dan Aneng Kiswantara. Dengan demikian, dapat dikatakan bahwa generasi ke tiga yang akan melanjutkan keberadaan pertunjukan wayang golek sedang berproses. Akan tetapi situasi pertunjukan Wayang Golek Ménak Sentolo sudah dapat dikatakan mati.

Kondisi pertunjukan Wayang Golek Ménak Sentolo khususnya pada tahun 2020-an, sangat memprihatinkan. Sejak tahun 1980an pertunjukan wayang tersebut mulai terpinggirkan hingga menjadi pertunjukan wayang langka. Dlanjutkan oleh putranya Sukarno, dan pengrawitnya bernama Suparman sebagai dalang, tetapi tanggapan masyarakat tidak seperti menanggapi pertunjukan dalang Widiprayitna. Pada saat ini masyarakat umum sangat jarang memanggil pertunjukan Wayang Golek Ménak Sentolo. Kini Wayang Golek Ménak Sentolo hanya dipentaskan di Bangsal Srimanganti Keraton Kasultanan Yogyakarta setiap Rabu pukul 10.00 hingga pukul 12.00 WIB, sebagai usaha untuk nguri-uri pertunjukan Wayang Golek Ménak Sentolo. B. M. S Riyanto berpendapat bahwa "Wayang Golek Jawa umumnya berbentuk tiga dimensi terbuat dari bahan utama kayu yang ditatah, diukir dan disungging atau diberi warna. Repertoar cerita menggunakan epos Mahabharata, Ramayana, dan kisah Amir Hamzah" (2018:5). Agak lain dengan ungkapan Trisno Santoso "Sedangkan di Cirebon, Tegal, Pekalongan, Tuban, Yogyakarta, Kebumen, Bojonegoro menggunakan cerita Ménak, Serat Panji, Babad Majapahit, dan bisa juga menggunakan cerita legenda daerah atau fiksi" (2016:4).

Fungsi dan manfaat pertunjukan wayang dalam kehidupan masyarakat, khususnya Jawa sangat erat dengan peristiwa -periswa kehidupan masyarakat seperti peristiwa pernikahan, bersih desa, menyongsong awal tahun dan lain sebagainya. Menurut Sunardi, pertunjukan wayang salah satunya dapat difungsikan sebagai sarana pendidikan untuk menyampaikan nilai-nilai kebangsaan kepada siswa sekolah dasar (2016:196). Pertunjukan wayang bagi masyarakat umum dapat digunakan sebagai sarana hiburan dan alat propaganda.

Masyarakat Jawa beranggapan, bahwa pertunjukan wayang tidak hanya hidup sebagai seni pertunjukan semata, tetapi dapat digunakan untuk mewadahi dan menjembatani berbagai kepentingan masyarakat, di antaranya untuk peringatan peristiwaperistiwa penting dalam kehidupan atau perjalanan hidup manusia sjak dalam kandungan hingga meninggal dunia (tin gkepan, sepasaran, selapanan, sunatan, mantenan, nyewu, ngijing, kol-kolan); untuk sarana pemujaan (upacara agama atau kepercayaan); un tuk peringatan hari-hari besar kenegaraan atau keagamaan; untuk kepentingan sosial; untuk sarana penyampaian ide-ide dan pesan pemerintah atau kelompok masyarakat; serta untuk tontonan dan tuntunan (2008:6).

Mengingat pentingnya fungsi dan manfaat pertunjukan wayang Golek maka perlu diadakan inovasi-inovasi untuk memajukan kembali. Dewanto Sukistono dalam disertasinyamengungkapkan perlunya langkah-langkah nyata sebagai usaha pengembangan Wayang Golek Ménak Sentolo dengan mengadakan pertunjukan ulang yang barengi dengan perubahan-perubahan yang mengarah kepada pengembangan lebih lanjut. Pengembangan dimungkinkan menyangkut segala bidang di antaranya; boneka wayang, struktur cerita, bahasa, karawitan, "bentuk pertunjukan, dan juga tidak kalah pentingnya adalah pengenalan pertunjukan Wayang Golek kepada generasi muda" (2013:337). Saran Dewanto Sukistono ini kiranya perlu ditanggapi dengan harapan pertunjukan Wayang Golek Menak mampu hidup kembali, tetapi untuk menghidupkan Wayang 
Golek Ménak Sentolo yang sudah mati tidak semudah membalikkan telapak tangan, perlu mengetahui faktor apa yang menyebabkan kematiannya, apakah pertunjukannya tidak menarik, atau ceritanya tidak dapat diikuti, atau hal-hal lain yang perlu dilakukan penelitian dengan serius.

Menurut Suparman (wawancara, 05 Desember 2017). "Boneka Wayang Golek Ménak Sentolo lebih kecil apabila dibandingkan dengan boneka Wayang Golek lain daerah, untuk itu kiranya perlu diperbesar, akan tetapi apabila diperbesar resikonya bobot boneka wayang menjadi lebih berat karena boneka Wayang Golek terbuat dari bahan utama kayu". Suparman juga mengatakan bahwa wayang golek teknik memainkannya lebih rumit apabila dibandingkan dengan teknik memainkan boneka wayang kulit. Hal ini, juga berpengaruh terhadap generasi muda yang malas yang enggan untuk belajar menjadi dalang Wayang Golek. Akan tetapi, mungkin juga akan berbeda perlakuannya apabila kehidupan pertunjukan Wayang Golek Ménak Sentolo laku di masyarakat. Penjelasan Suparman tentang besarnya boneka wayang kiranya juga perlu mendapat perhatian barangkali mampu menjadi salah satu cara untuk melestarikan pertunjukan Wayang Golek Ménak Sentolo, atau setidak-tidaknya mengenalkan kembali pertunjukan wayang. Akan tetapi, melakukan perubahan dengan cara memperbesar boneka wayang agar mampu dilihat dari jarak jauh akan menjemukan bagi penonton karena wajah boneka terlihat seolaholah sama. Untuk itu perlu mengadakan eksplorasi yang sungguh-sungguh untuk menemukan boneka wayang besar akan tetapi ringan untuk dimainkan.

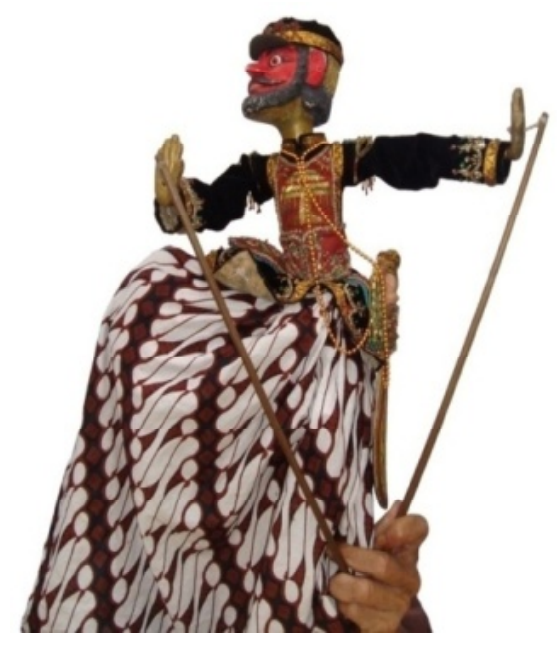

Gambar 1.Tokoh Umarmaya Wayang Golek Ménak Yogyakarta dengan bahan utama kayu (Dokumentasi foto Trisno Santoso, 2016)
Pertunjukan Wayang Golek Ménak Sentolo juga menampilkan boneka wayang hewan seperti kuda, gajah, ular, harimau, babi hutan, macan, singa dan lain-lain. Hanya satu binatang yang tidak pernah tampil yaitu binatang unta, pada hal lakon yang dipertunjukkan adalah lakon-lakon yang mengisahkan kejadian di tanah Arab dan sekitarnya. Untuk membuat boneka wayang hewan bahan utama yang digunakan adalah kulit lembu atau kulit kerbau. Adapun khusus untuk boneka wayang kuda menggunakan bahan utama kayu. Di samping itu pertunjukan Wayang Golek Ménak Sentolo juga menggunakan kayon dengan bahan utama kulit seperti pada pertunjukan Wayang Kulit Purwa (Soetarno, 1990:32). Bahan utama pembuatan Wayang Golek adalah kayu terpilih yang mempunyai beberapa keunggulan tertentu utamanya berberat jenis ringan, ulet, dan lunak (empuk). Bahan utama pembuatan kepala Wayang Golek di masing-masing daerah mempunyai pilihan kayu tersendiri yang umumnya terdapat di daerah masing-masing Wayang Golek tersebut hidup dan berkembang. Selain itu, biasanya bahan utama yang digunakan untuk pembuatan kepala Wayang Golek tidak dimanfaatkan sebagai bahan utama bangunan seperti; kerangka rumah, almari, meja, kursi dan lainlain. Di Yogyakarta bahan utama pembuatan kepala Wayang Golek dan tangan menggunakan kayu Pule, dan kayu Waru, selanjutnya di daerah Kabupaten Kebumen menggunakan kayu jaranan. Bahan utama pembuatan Wayang Golek di Tegal, Batang, serta Pekalongan menggunakan kayu dondong jaran. Adapun bahan utama pembuatan badan boneka Wayang Golek di Kebumen dan di Yogyakarta menggunakan kayu bunga kenanga. Bahan kayu bunga kenanga dipilih karena berat jenisnya lebih kecil apabila dibandingkan dengan kayu jaranan, pule, serta waru. Dengan demikian diharapkan boneka wayang akan lebih ringan, berbeda apabila bahan utamanya kayu jaranan, kayu waru, atau kayu pule semua. Kayu bunga kenanga tidak dimanfaatkan sebagai bahan pembuatan kepala boneka wayang karena lebih rapuh dan mudah patah. Kayu waru, kayu pule, kayu jaranan, maupun kayu dondong jaran kini mulai langka karena tidak dibudidayakan penanamannya. Kayu-kayu tersebut tumbuh secara liar karena biasanya hanya digunakan sebagai kayu bakar atau pagar. Dengan demikian dimungkinkan kayu bahan utama pembuatan Wayang Golek akan semakin langka, karena tidak dibudidayakan penanamannya. Kiranya tidak berlebihan apabila perlu memikirkan dan melakukan tindakan untuk ikut menjaga lingkungan agar pohon tumbuh tidak begitu mudahnya ditebang untuk 


\section{GEEAR Jumal sai isulya}

membuat boneka wayang golek tanpa diikuti dengan penanaman pohon baru. Dengan demikian, perlu mengambil tindakan pembuatan boneka wayang golek yang menghasilkan boneka wayang lebih besar, ringan, dan ramah lingkungan.

Perkembangan pertunjukan wayang Golek sejalan dengan pemikiran Derrida dalam disertasi (Karya Seni) Trisno Santoso bahwa makna dari tanda dapat mengalami perubahan dan selalu menerima untuk terjadinya pandangan baru dan tafsir baru yang selalu terbuka (Santoso, 2016:12). Demikian juga budaya yang termasuk di dalamnya kesenian sejak dulu kala selalu mengalami perubahan dan perkembangan bahkan tidak ada kehidupan kesenian yang dapat dikatadepankan tetap. Perubahan ini dapat berupa perkembangan ke arah masa kini tetapi juga dapat kembali ke masa yang telah lalu.

\section{B. Metode}

Penelitian ini difokuskan di wilayah Sentolo, Kabupaten Kulon Progo, Daerah Istimewa Yogyakarta. Dipilih daerah tersebut karena munculnya kembali pertunjukan Wayang Golek Ménak di Daerah Istimewa Yogyakarta diawali dari daerah Sentolo. Selain itu juga terdapat pengrajin Wayang Golek dan dalang Wayang Golek yang memiliki pengalaman panjang dengan pertunjukan dan pembuatan Wayang Golek Ménak Sentolo. Mereka adalah para generasi yang bertindak sebagai dalang Wayang Golek, dan juga generasi pembuat boneka Wayang Golek. Diawali dengan tehnik pengumpulan data dilakukan dengan cara studi pustaka, buku maupun tulisan yang mengetengahkan tentang pertunjukan Wayang Golek Ménak Sentolo, proses di lapangan mengalami kendala karena tulisan tentang Wayang Golek Ménak Sentolo ini tidak banyak jumlahnya, kemudian didukung melalui wawancara dengan tokoh tua sebagai saksi pertunjukan wayang golek, pengrawit, dan dalang wayang golek di daerah tersebut yang kini rata-rata sudah tua. Banyak masyarakat angkatan tahun 1935-an yang tidak dapat menceritakan secara urut dan rinci tentang pertunjukan Wayang Golek Ménak Sentolo karena mereka ratarata sudah lupa, kini rata-rata umur para saksi pertunjukan Wayang Golek sudah mendekati 80 tahunan.

Fokus Group Diccuscion dilakukan untuk menjaring pendapat dari para ahli dan pelaku Wayang Golek Ménak. Diskusi ini membicarakan tentang perkembangan Wayang Golek Ménak Sentolo di saat ini, serta kemungkinan perkembangan selanjutnya. Kemudian dilanjutkan dengan observasi dengan mengamati pertunjukan Wayang Golek di Yogyakarta dan sekitarnya, di antaranya di Salamrejo, Sentolo, Kulon Progo, Daerah Istimewa Yogyakarta dengan dalang Sukarno, kemudian di hari yang lain dilanjutkan dengan mengamati pertunjukan Wayang Golek Ménak dengan dalang Suparman di Bangsal Sri Manganti Keraton Kasultanan Yogyakarta, juga mengamati boneka Wayang Golek yang terdapat di musium, kemudian juga di laboratorium. Analisis data menggunakan teori inovasi untuk mengungkapkan proses pembaruan pembuatan boneka Wayang Golek yang ramah lingkungan, sedangkan laboratorium digunakan untuk melakukan percobaan-percobaan pembuatan boneka Wayang Golek yang diperbesar. Tujuan dari laboratorium ini adalah menghasilkan boneka Wayang Golek yang wujudnya tampak besar, akan tetapi berbobot ringan apabila dimainkan oleh dalang. Selama ini boneka Wayang Golek Ménak Sentolo ukurannya lebih kecil apabila dibandingkan dengan boneka Wayang Golek di Jawa Barat, Tegal, dan Pekalongan. Boneka Wayang Golek Ménak Sentolo perlu untuk diperbesar, akan tetapi perlu pemikiran agar boneka wayang besar tersebut berbobot ringan. Hal ini juga mempunyai harapan yang lain, yaitu diharapkan agar anak-anak usia Sekolah Dasar (SD) ikut tertarik untuk bermain-main dengan boneka Wayang Golek yang berbobot ringan yang pada muaranya anak-anak usia Sekolah Dasar tertarik untuk belajar memainkan boneka Wayang Golek. Selain metode yang telah diutarakan juga menggunakan metode empiris, serta segala sesuatu hal yang pernah dilakukan dan tidak dibukukan. Pengalaman menemukan pembuatan badan boneka wayang didapat pada waktu ikut membuat tempat penyimpanan blangkon (jw: klebut), dan pembuatan thothok kepala pada irah-irahan busana tari ataupun busana Wayang Orang. Pada pembuatan klebut menggunakan bahan baku kertas bekas pembungkus semen, sedangkan pada pembuatan thothok irahirahan busana Wayang Orang menggunakan kertas koran. Hal ini dilakukan karena kertas bekas pembungkus semen sangat keras tidak dapat ditembus dengan jarum, sedangkan dalam pembuatan irah-irahan butuh ditempel dengan asesoris yang lain seperti jamang, nyamat, utah-utahan, makara dan lainlain dengan menggunakan jarum. Dari pengalaman inilah kemudian dipastikan bahwa untuk membuat badan boneka Wayang Golek yang ringan dan kuat menggunakan kertas bekas pembungkus semen. Kendatipun demikian, pembungkus semen juga tidak berkwalitas sama, maka dalam memilih kertas semen perlu dipilah diantara pembungkus semen yang 
terkuat karena ada beberapa pabrik semen yang menggunakan kertas bahan pembungkus tidak sama. Di samping itu, lapisan kertas pembukusnya banyak lembarnya juga bervariasi, ada yang 2 lapis, ada yang 3 lapis, dan ada yang menggunakan 4 lapis.

\section{Pembahasan}

Bobot kepala boneka wayang dengan bahan utama dari kayu pule, waru, jaranan, dondong jaran, dan kayu albasiyah berbeda-beda. Dari beberapa bahan utama kayu tersebut maka kayu albasiyah adalah kayu yang berbobot paling ringan. Untuk itu, ditentukan pembuatan kepala boneka Wayang Golek agar lebih ringan menggunakan bahan utama kayu albasiyah. Pengurangan bobot boneka selain dari kepala boneka wayang juga dapat dikurangi dari berat badan boneka wayang, kemudian timbulah pemikiran bahwa salah satu cara untuk mengurangi bobot boneka wayang dengan cara mengurangi bobot badan boneka wayang. Untuk mengurangi bobot badan boneka wayang dengan cara membuat rongga pada badan boneka wayang, tetapi apabila badan wayang dikeruk dalamnya hingga tipis badan boneka wayang dipandang dari segi kekuatannya dimungkinkan badan boneka wayang mudah pecah. Maka satu-satunya cara yang dapat ditempuh hanya dengan cara dicetak. Maka tinggal memikirkan bahan utama yang digunakan sebagai bahan badan boneka wayang yang dapat dicetak, kuat dan bernilai ekonomi rendah. Berdasarkan dari pengalaman yang didapat kemudian ditentukan bahan utama pembuatan badan boneka wayang, yaitu bahan kertas bekas pembungkus semen. Sedankan bahan utama pembuatan kepala boneka wayang menggunakan kayu albasiyah.

Alasan lain mengapa menggunakan bahan utama kayu albasiyah atau kayu sengon Laut karena kayu albasiyah dibudidayakan penanamannya secara besar-besaran. Kayu albasiyah berkembang lebih cepat dan dibudidayakan karena manfaatnya lebih menjanjikan. Kayu albasiyah dapat digunakan sebagai bahan pembuatan kertas, kayu lapis, ataupun bahan bangunan rumah seperti kerangka atap, kusen pintu, dan lain sebagainya. Sedangkan kayu waru, pule, jaranan, dondong jaran tidak dibudidayakan penanamannya, karena perkembangannya tidak secepat kayu albasiyah dan juga manfaatnya kurang menjanjikan. Kayu albasiyah ditanam dalam jangka waktu 10-15 tahun sudah bisa ditebang untuk dimanfaatkan atau dipanen untuk dijual, sedangkan kayu jaranan, pule, dondong jaran, waru dalam jangka puluhan tahun baru dapat dimanfaatkan.

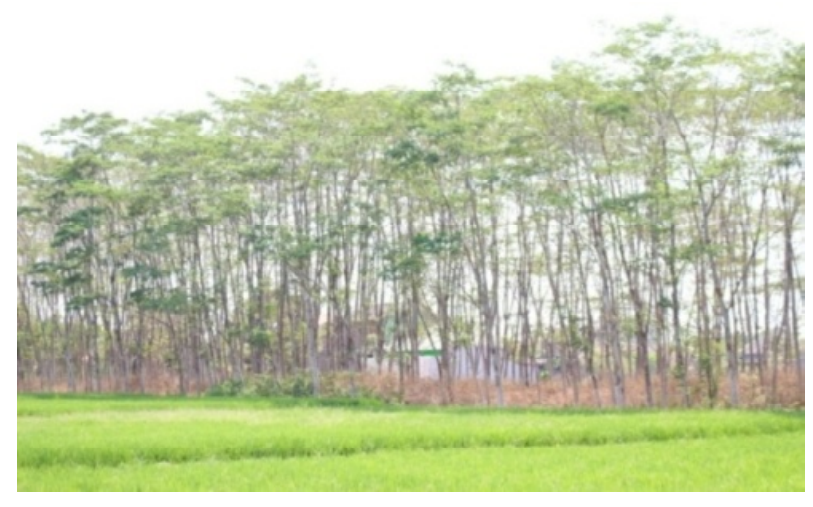

Gambar 2. Pohon albasiyah yang dibudidayakan (Dokumentasi foto Kusnanta RG, 2016)

Aldi Hendrawan mengungkapkan, bahwa unsur-unsur teknologi dan inovasi menjadi konsekuensi logis, juga bisa dimanfaatkan sebagai solusi untuk memecahkan persoalan (2017:4). Pikiran ini dijadikan dasar untuk mencoba menawarkan wayang inovasi baru dengan memberikan sentuhan dan mengubah pada bahan utama pembuatan kepala, bahan utama pembuatan badan boneka wayang dan bahan utama pembuatan busana serta asesorisnya. Setelah melalui percobaan beberapa tahap pada akhirnya ditemukan pembuatan boneka Wayang Golek baru yang ringan apabila dimainkan, tidak merusak lingkungan dengan menebang kayu sebagai bahan utama pembuatan Wayang Golek. Boneka ini dengan bahan ini justru ikut menjaga lingkungan dengan memanfaatkan bahan utama limbah. Untuk pembuatan kepala boneka wayang menggunakan bahan utama dahan kayu albasiyah, pembuatan badan boneka wayang menggunakan limbah kertas bekas pembungkus semen, sedangkan pembuatan tangan bagian telapak tangan hingga siku menggunakan ranting-ranting kayu albasiyah, dan tangan bagian lengan atas menggunakan bahan dakron yang dibungkus dengan kain perca. Kemudian untuk pembuatan boneka wayang hewan kuda menggunakan bahan utama styrofoam bekas, lem kayu, dan kertas bekas pembungkus semen.

Pembuatan busana wayang menggunakan bahan utama kain-kain perca. Eksplorasi ini dilakukan dalam rangka memanfaatkan kain-kain perca dari perancang busana yang biasanya menggunakan kainkain berharga mahal dan dari bahan tersebut dapat dipastikan tersisa, tetapi sudah tidak dapat dimaanfaatkan untuk busana manusia, karena sisasisa kain biasanya terlalu kecil. Kain-kain perca berharga mahal ini di samping memanfaatkan limbah juga memberikan karakter pada tokoh-tokoh boneka 


\section{GEEAR Jumal sai isulya}

wayang. Selain memberikan asesoris dengan kain perca berbahan mahal untuk memberikan karakter pada kepala boneka wayang dilakukan dengan jalan memberikan tambahan tata rias yang berbeda seperti layaknya merias wajah manusia yang mengacu pada rias wajah teater dan film. Dengan menggunakan bahan-bahan seperti, rajut bekas, bulu mata bekas, rambut sintetis bekas. Sehingga untuk membuat boneka Wayang Golek ringan adalah dengan cara membuat kepala boneka dengan beberapa jenis wayang seperti tokoh gagahan, tokoh alusan, tokoh putren, tokoh tua. Selanjutnya untuk sentuhan karakter detail wajahnya disempurnakan dengan rias karakter. Sedangkan untuk badan boneka wayang hanya dengan mencetak beberapa ukuran badan boneka wayang. Misalnya badan boneka besar, badan boneka sedang, badan boneka kecil, dan badan boneka putri. Untuk pembuatan boneka ringan ini salah satu cara yang ramah lingkungan dengan memanfaatkan limbah yang menumpuk di sekitar lingkungan seperti; kertas koran, kertas bekas pembungkus semen, steroform bekas pengganjal barang-barang elektronik seperti; pengganjal kulkas, pengganjal TV, pengganjal mesin cuci dan lain lain, yang biasanya berakhir menjadi limbah yang mengotori lingkungan.

Pembuatan wayang golek dengan bahan limbah merupakan upaya terobosan untuk ikut menjaga lingkungan bagi para pengrajin wayang golek, sedangkan bagi dalang-dalang wayang golek dengan bahan utama limbah ini bobot boneka wayang akan menjadi semakin ringan apabila dibandingkan dengan wayang golek dengan bahan utama kayu jaranan, pule, waru, atau dondong jaran. Selain itu, bahan limbah ini bebas dari hama kayu, biasanya boneka wayang yang terbuat dari bahan utama kayu rawan dimakan hama kayu.

Berat Boneka Wayang Golek dengan kepala yang terbuat dari bahan utama kayu pule, waru, jaranan, dan dondong jaran berkisar antara 250 sampai dengan 300 gram untuk boneka wayang jenis putren atau wayang perempuan, 300 sampai dengan 350 gram untuk jenis bambangan atau kesatriya muda, 350 sampai dengan 500 gram jenis katongan atau wayang raja, dan 500 sampai dengan 750 gram jenis gagahan, dan raksasa. Sedangkan boneka hewan kuda berbobot 1400 gram.

Hasil yang dicapai pada eksplorasi pembuatan boneka wayang golek dari bahan limbah dapat mengurangi bobot antara $30 \%$ sampai dengan 50\% lebih ringan apabila dibandinglkan dengan bobot boneka wayang dari bahan utama kayu, yaitu berkisar antara 175 sampai dengan 225 gram untuk boneka wayang jenis putren atau wayang perempuan, 200 sampai dengan 300 gram untuk jenis bambangan atau kesatriya muda, 300 sampai dengan 350 gram jenis katongan atau wayang raja, dan 400 sampai dengan 550 gram jenis gagahan, dan raksasa.

\section{Cara Pembuatan Wayang Golek Berbahan Limbah Kertas}

\section{Pembuatan Kepala}

Pertama yang dilakukan untuk pembuatan kepala boneka adalah pemilihan bahan utama yaitu dahan kayu albasiyah, dipilih dahan karena tidak perlu menebang pokok pohon. Hal ini, dilakukan sebagai salah satu cara untuk menjaga lingkungan. Selain itu,dahan kayu albasiyah ini dipilih karena berbobot ringan dan tidak mudah diserang hama kayu. Kepala boneka wayang akan dibuat tanpa menggunakan ukiran asesoris kepala seperti mahkota, topong dan lain sebagainya akan tetapi kepala boneka wayang dibuat botak atau (gundulan). Untuk pembuatan kepala yang berlingkar $28 \mathrm{~cm}$, panjang dari batas kepala bagian atas sampai batas leher $17 \mathrm{~cm}$ diperlukan dahan kayu albasiyah dengan garis tengah $12 \mathrm{~cm}$, dan panjang $17-18 \mathrm{~cm}$
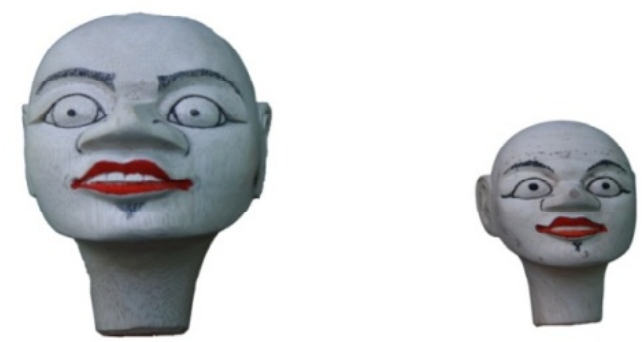

Gambar 3. Kepala Boneka wayang dengan bahan utama kayu albasiyah yang sudah diperhalus permukaannya, belum diberi asesoris kepala (gundhulan)

(Dokumentasi foto Kusnanta RG, 2017)

\section{Pewarnaan}

Pewarnaan boneka Wayang Golek menggunakan bahan utama dari cat tembok putih, sedangkan untuk membuat macam-macam warna seperti biru, merah, kuning ditambah dengan tetesan bahan pewarna sablon dan sedikit lem kayu agar tidak mudah luntur. Sedangkan untuk warna kuning emas menggunakan bubuk prada, brouwn atau kertas foil 
bahan cetak sablon. Lem kayu selain digunakan sebagai pelengket atau perekat, juga digunakan untuk polesan terakhir sebagai pelindung warna agar kelihatan berkilau dan tidak mudah luntur, istilah Jawa untuk ngedus. Adapun caranya adalah, lem kayu dicampur dengan sedikit air hingga merata dan menjadi agak cair, kemudian disapukan ke seluruh warna secara merata. Untuk menjalankan proses atau pengerjaan ngedus dilakukan setelah sunggingan atau pewarnaan selesai sempurna dan betul-betul kering, karena apabila belum betul-betul kering akan berpengaruh pada kebersihan sunggingan atau dimungkinkan warna yang terkena cairan bahan dusdusan akan merusak warna di dekatnya, sehingga sunggingan menjadi rusak.

Perlu diketahui bahwa perwarnaan pada boneka wayang ini hanya dilakukan untuk memberi warna pada kulit tangan bagian siku sampai dengan telapak tangan dan memberi warna kulit pada raut muka atau wajah. Garis-garis dengan warna hitam digunakan untuk merias wajah atau memberikan garis lekuk sesuai dengan karakternya.

\section{Pembentukan Karakter}

Tahapan selanjutnya setelah diberi warna kulit adalah proses pembentukan karakter dengan merias wajah boneka yang sesuai karakter yang dibutuhkan dengan cara merias wajah boneka. Untuk memberikan garis-garis wajah dapat menggunakan cat tembok warna hitam atau dapat juga dengan menggunakan tinta black. Dalam merias wajah boneka ini dapat juga dengan menambah kumis tempel, jambang tempel, rambut tempel dengan bahan rambut sinteses atau rajut. Selanjutnya dipasang asesoris kepala boneka wayang sesuai dengan karakter tokoh dengan menggunakan bahan utama kain perca. Seperti; kopyah, songkok, ubel, udheng, mahkota, surban, jamang, dengan bahan kain perca, atau oscar perca dari sisa-sisa pembuat tas atau sepatu, dan jaket. Pembuatan kepala boneka hanya membutuhkan beberapa model dasar yang pada akhirnya dapat disempurnakan dengan tambahan rias wajah yang mengubah bentuk dasarnya, seperti model tokoh bermata bulat, gabahan, dan kedelen, juga model tokoh tua, model tokoh putri, dan lain-lain. Hal ini dimaksudkan agar pembuatan kepala lebih mudah dan cepat pengerjaannya.

\section{Pembuatan Badan Boneka Wayang}

Pembuatan badan boneka wayang, agar berongga menggunakan bahan utama kertas bekas pembungkus semen. Pada awalnya membuat badan boneka wayang menggunakan bahan utama kayu atau tanah liat, badan boneka ini tanpa lengan tetapi hanya sebatas bahu. Badan boneka ini akan digunakan untuk mencetak calon badan boneka wayang. Setelah badan boneka dari kayu terbentuk kemudian digergaji membujur pada sisi kiri atau sisi kanan badan hingga sampai di sumbu badan atau tidak sampai terbelah menjadi dua, paroan gergaji pada badan menjadi sisi belakang dan sisi depan. Badan boneka kayu yang sudah digergaji sebelah kemudian dibalut dengan plastik halus hingga penuh dan padat, selanjutnya ditempel dengan isolasi kertas sampai membungkus badan seutuhnya, dan selanjutnya ditempel dengan potongan-potongan kertas bekas pembungkus semen dengan perekat lem kayu. Agar kelihatan halus ukuran potongan kertas, yaitu antara $3 X 4 \mathrm{~cm}$, atau $2 X 3 \mathrm{~cm}$. Alasan menggunakan kertas bekas pembungkus semen karena apabila kering akan menjadi keras dan tahan banting. Setelah kurang lebih 3-4 lapis badan kayu dikeluarkan dengan membelah badan boneka dengan kater atau pisau tipis mengikuti belahan gergaji, kemudian dilanjutkan dengan menyambungkan bekas goresan dan mempertebal lapisan badan boneka wayang hingga 6-8 lapisan. Badan boneka wayang dijemur sampai kering kemudian diberi lubang pada bagian leher boneka dan bagian bawah. Untuk memperkuat dan memperkeras dapat dioles dengan resin, tetapi seandainya tidak dioles resin maka badan boneka sudah keras. Pembuatan badan boneka wayang dengan bahan kertas bekas pembungkus semen ini akan menghasilkan calon badan boneka wayang berbobot 80 gram, sedangkan badan boneka wayang dengan bahan utama kayu berbobot 240 gram. Dengan demikian, bobot badan boneka wayang dari bahan kertas bekas pembungkus semen hanya berbobot 30 $\%$ dari badan boneka wayang dengan bahan utama kayu. Selain itu, pembuatan badan boneka wayang dengan bahan utama kertas ini mengurangi penumpukan limbah kertas semen bekas.

\section{Pembuatan Tangan}

Selanjutnya dilakukan pembuatan tangan yaitu membuat tangan dengan bahan serpihan-serpihan kayu atau papan untuk membuat tangan bagian siku sampai dengan telapak tangan. Adapun bagian siku sampai dengan telapak tangan untuk boneka wayang golek terdapat tiga jenis telapak tangan sesuai dengan jenis tokohnya yaitu, 1) telapak tangan jenis ngrayung, (putri, bambangan, raja), 2) telapak tangan jenis kithingan,(raksasa), dan 3) telapak tangan jenis tapukan (boneka wayang gecul). Tahap pembuatan 


\section{GE[AR Jumal Sori Bublya}

tangan dilanjutkan dengan pengerjaan tangan pada bagian lengan atas. Untuk membuat tangan bagian lengan atas adalah dengan menggunakan bahan utama dakron yang dibungkus dengan kain perca seperti layaknya membuat guling, kemudian disambungkan dengan bagian siku sampai telapak tangan dengan menggunakan lem kertas dan dijahit agar lebih kuat.

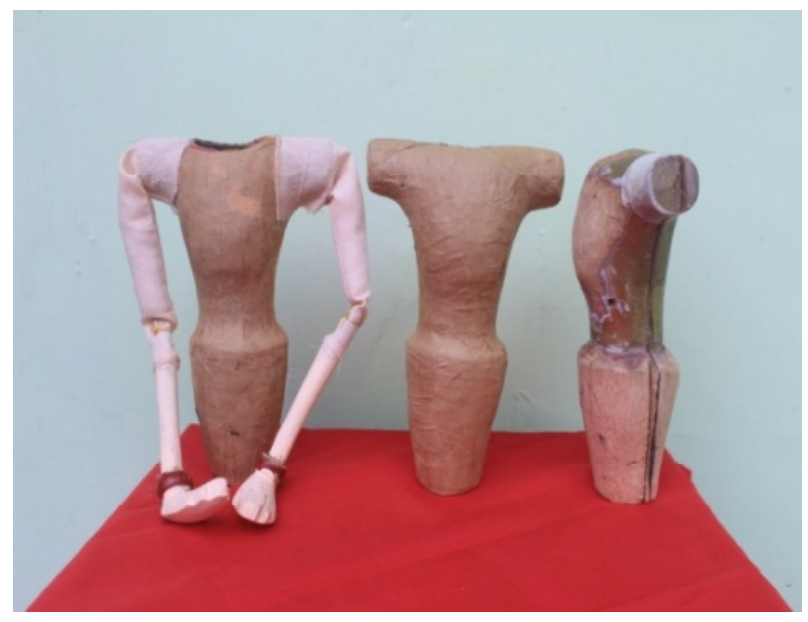

Gambar 4. Calon badan boneka dengan bahan kertas bekas pembungkus semen, paling kanan adalah master positif untuk mencetak badan boneka (Dokumentasi foto Kusnanta RG, 2018)

\section{Merangkai Tangan dengan Badan}

Tahap berikutnya adalah merangkai tangan boneka dengan badan boneka wayang. Untuk merangkai tangan dengan badan boneka wayang perlu memperhitungkan dengan rancangan busana selanjutnya. Hal ini berarti, perlu melihat rancangan busana selanjutnya apakah akan menggunakan busana yang tertutup atau terbuka/tanpa baju, apabila rancangan selanjutnya tanpa menggunakan baju maka pada bagian lengan atas kain yang dipilih harus disesuaikan warnanya dengan warna badan boneka wayang. Setelah dipastikan tangan ditempelkan pada badan boneka wayang dengan menempelkan tangan pada bagian lengan atas atau kain pembungkus dakron bagian ujung ditempelkan sehingga membungkus bahu badan boneka wayang dengan perekat lem kertas.

\section{Membuat Busana}

Membuat busana boneka adalah tahap yang memerlukan rancangan agak rumit karena harus memikirkan model busana yang sesuai dengan kedudukan, asal tokoh, usia, jenis kelamin yang memerlukan konsep yang perlu dipikirkan dengan matang. Dalam rancangan busana wayang bahan limbah ini mengacu pada busana kethoprak, wayang wong, teater modern, dan wayang golek.

Desain baru busana boneka wayang dibuat dengan memanfaatkan limbah kain dari penjahit busana. Busana boneka wayang baru ini dirancang juga dengan mengacu busana wayang yang pernah ada kemudian dikembangkan. Kelengkapan busana pada kepala wayang dirancang dengan tempelan yang disesuaikan dengan karakter tokoh. Selain itu, juga dirancang busana boneka wayang agar sesuai dengan kedudukan tokoh, usia, serta sifat tokoh pada pilihan cerita. Bahan busana yang digunakan dapat dari kain, kulit, oscar, dan asesoris paiyet yang dirancang agar mampu menampilkan keindahan yang sesuai dengan karakter bonekanya. Di samping itu, juga dirancang asesoris-asesoris pendukung busana seperti gelang, kalung, subang, anting, dan lain sebagainya yang disesuaikan dengan kedudukan, karakter, usia, serta sifat tokoh. Tidak kalah pentingnya perlu diutarakan bahwa untuk merancang busana boneka juga memilih pola-pola gambar yang mempertimbangkan pola-pola motif gambar yang sesuai dengan besar boneka. Pola motif terlalu besar sedangkan boneka wayang kecil maka kurang enak apabila dipandang, demikian juga apabila menggunakan busana yang bermotif garis atau kotak disarankan untuk memikirkan kepatutan sehingga antara boneka dengan busananya terlihat serasi.

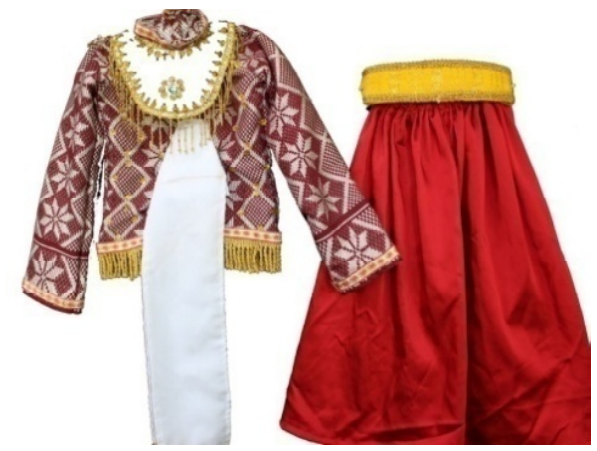

Gambar 5. Salah satu busana wayang boneka (Dokumentasi foto Kusnanta RG, 2017)

\section{Memasang Busana}

Tahap selanjutnya yaitu merangkai boneka wayang dengan memberi baju dan kain yang menyerupai pemakaian sarung. Untuk sarung wayang sengaja diubah dengan bahan yang tidak bermotif batik. Hal ini dilakukan untuk memberikan lahan kreativitas pada bagian kain yang sesuai dengan karakter wayang. Alasan lain tidak menggunakan kain bermotif batik, karena pola kain batik umumnya 
berpola besar-besar sehingga harus memperkecil pola. Sebagai contoh; pola kain bermotif kawung didesain untuk dipakai manusia, sehingga apabila dipakai untuk boneka wayang pola kawung tersebut kurang pas untuk ukuran boneka wayang, kecuali kalau ada pola kawung yang ukurannya kecil-kecil.

\section{Merangkai Boneka Wayang}

Akhir pada pembuatan Wayang Golek Ringan Pemanfaatan Limbah Sebagai Pengembangan Boneka Wayang Golek adalah merangkai badan boneka dan kepala dengan gapit wayang atau sogol. Khusus sogol menggunakan bahan utama kayu pinang. Bahan ini dipilih karena berserat lurus dan kalau benar tua bersifat keras. Di samping itu, pemanfaatan kayu pinang atau pucangljambé karena kayu tersebut termasuk kayu yang tidak dapat digunakan sebagai bahan bangunan. Di desa kayu pinang digunakan untuk jembatan parit antara petak sawah yang satu dengan petak yang lain, atau untuk mengalirkan air karena bagian tengah kayu pucang lunak seperti gabus, serta panjang. Setelah badan boneka dengan kepala boneka terangkai, kemudian memberi tuding pada tangan boneka wayang. Untuk tuding atau tangkai tangan boneka wayang dipilih bahan utama bambu beruas panjang, sehingga dalam satu tangkai hanya terdapat satu ruas yang kemudian diberi lubang agar lebih awet, karena pada bagian ruas bambu lebih keras dan kuat. Di samping itu juga dipilih bambu yang lurus.

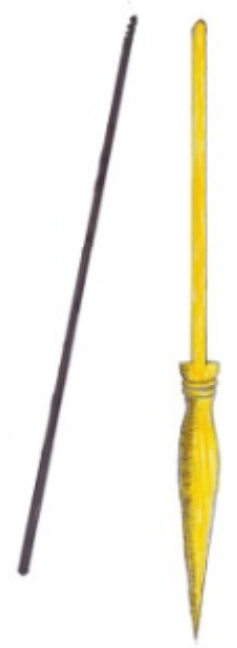

Gambar 6. Tuding atau tangkai wayang dan sogol atau gapit, sumbu penghubung antara badan boneka wayang dengan kepala wayang. (Dokumentasi foto Trisno santoso, 2016)

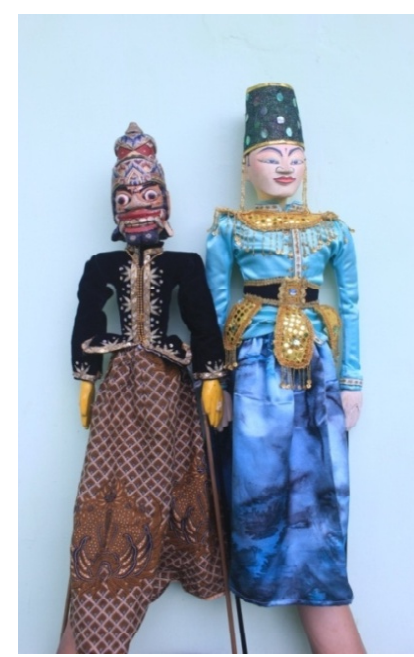

Gambar 7. Gambar kiri, wayang dengan bahan utama kepala kayu jaranan dan badan dari bahan kayu bunga kenanga dengan bobot 750 gram, gambar kanan wayang dengan bahan kepala kayu albasiyah dan badan dari kertas bekas pembungkus semen berbobot 470 gram

(Dokumentasi foto Kusnanta RG, 2018)

\section{Membuat Boneka Wayang Hewan/kuda}

Pada pertunjukan wayang golek menak Yogyakarta menampilkan kuda tunggangan dari bahan utama kayu jaranan. Bboneka wayang kuda ini terlihat kecil apabila dibandingkan dengan boneka wayang yang menungganginya. Hal ini, apabila dipandang kurang serasi, karena besar boneka antara penunggang dan kuda perbedaan figur besarnya tipis. Untuk itu, dilakukan ekplorasi dengan bahan yang ringan dengan limbah sterooform yang kemudian dibalut dengan kertas bekas pembungkus semen.

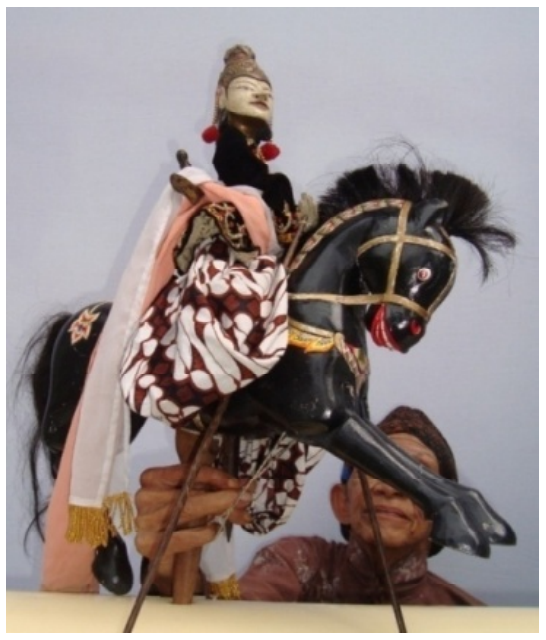

Gambar 8. Boneka wayang kuda dengan bahan utama kayu.

(Dokumentasi Foto Dewanto Sukistono, 2013) 


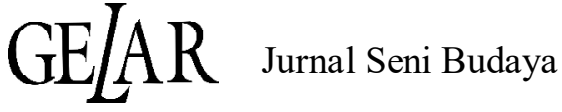

Membuat boneka wayang hewan kuda dengan menggunakan bahan utama dari stereoform, lem kayu, dan kertas bekas pembungkus semen memang harus mempunyai kepandaian membuat patung, tetapi ini bisa dipelajari dengan menggunakan model sketsa. Caranya adalah; Stereoform bekas pengganjal barangbarang elektronik disambung-sambung sesuai dengan kebutuhan untuk membuat kepala sampai dengan leher dengan alat pahat cutter serta gergaji besi, setelah terbentuk kemudian dilapisi dengan kertas semen bekas 3 sampai 5 lapis menggunakan lem kayu. Dilanjutkan dengan membuat badan hewan kuda, setelah terbentuk kemudian juga dilapisi dengan kertas semen bekas 3 sampai 5 lapis. Untuk rambut dan ekor kuda dapat menggunakan limbah ekor sapi yang didapat dari tempat penyembelihan hewan. Apabila membutuhkan pewarnaan rambut untuk menyesuaikan dengan badan kuda dapat menggunakan semir rambut. Pengerjaan ini mampu menghasilkan boneka hewan kuda dengan bobot berat 350 gram, sedangkan hewan kuda dengan bahan utama kayu berbobot berat 1400 gram.

Perubahan yang dilakukan dalam pembuatan hewan kuda ini adalah mengubah estetik gerak kuda dengan memindahkan anggota badan yang bergerak. Hewan kuda yang pernah ada pada pertunjukan Wayang Golek Ménak Yogyakarta digerakkan pada bagian kaki dengan cara memotong bagian kaki depan pada batas pangkal paha, kemudian disambungkan dengan menggunakan pasak sehingga kaki tersebut dapat bergerak-gerak. Selanjutnya, pada pangkal paha tersebut antara kaki yang satu dengan kaki yang lain (kaki kanan dan kaki kiri) dihubungkan dengan tali. Dengan demikian, apabila tali ditarik maka kaki depan kuda dapat bergerak-gerak, sedangkan pada kaki belakang juga dibuat sama dengan kaki depan tetapi tidak diberi tali. Sedangkan kuda pada wayang boneka bahan limbah sterooform yang dapat bergerak pada bagian leher dengan cara memutus antara leher dengan bahu kuda kemudian disambungkan dengan di dalamnya diberi besi plat yang lentur dibentuk huruf $\checkmark$ sehingga kepala kuda dapat bergerak menganggukangguk. Tehnik ini diharapkan akan mampu memancing imajinasi kuda lari dengan langkah yang lebih lebar dibandingkan dengan gerak pada kaki kuda.

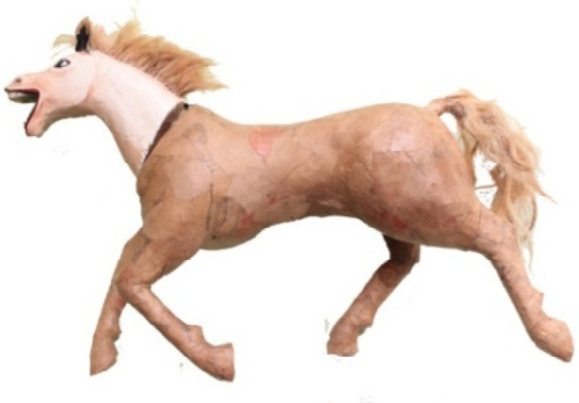

Gambar 9. Boneka hewan kuda yang belum diberi warna serta busana

(Dokumentasi foto Kusnanta RG, 2018)

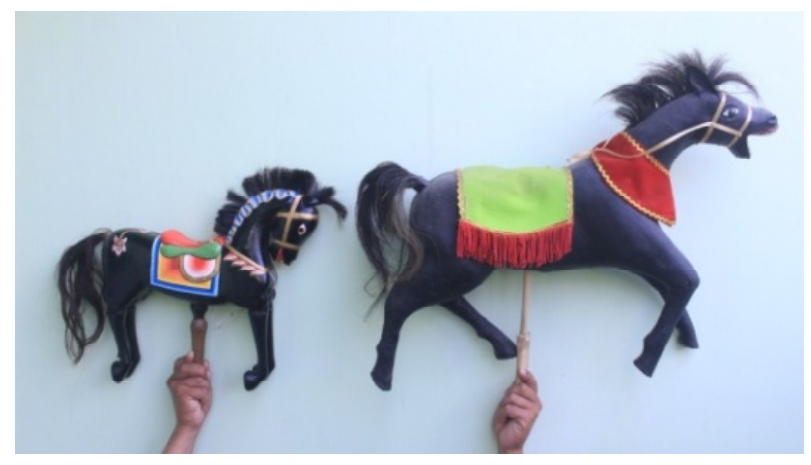

Gambar 10. Kiri boneka hewan kuda bahan utama kayu berbobot 1400 gram dan kanan hewan kuda dengan bahan sterooform bekas dengan bobot 750 gram.

(Dokumentasi foto Kusnanta RG, 2018)

\section{Kesimpulan}

Pada masa sekarang kondisi pertunjukan Wayang Golek Ménak Sentolo khususnya di Yogyakarta sangat memprihatinkan. Oleh karena itu, diperlukan langkah-langkah nyata sebagai usaha pengembangan untuk menghidupkan kembali pertunjukan Wayang Golek Ménak Sentolo. Pengembangan dimungkinkan menyangkut segala bidang di antaranya, boneka wayang, struktur cerita, bahasa, iringan, bentuk pertunjukan, dan juga tidak kalah pentingnya adalah pengenalan pertunjukan Wayang Golek kepada generasi muda.

Boneka Wayang Golek bahan utama limbah adalah boneka wayang baru sebagai salah satu usaha untuk mengembangkan boneka Wayang Golek yang belum digunakan oleh pertunjukan Wayang Golek 
secara umum. Usaha ini dapat menghasilkan boneka wayang besar dengan bobot ringan.

Pembuatan wayang boneka ringan ini sudah dikerjakan atau melalui eksplorasi sejak tahun 2015 dengan berbagai bahan untuk menemukan boneka wayang yang ringan akan tetapi juga kuat atau awèt. Di samping itu boneka wayang baru sudah dipentaskan beberapa kali baik oleh anak-anak ataupun remaja dan hasilnya mendapatkan tanggapan yang menyenangkan.

Eksplorasi pembuatan boneka Wayang Golek dengan pertimbangan bahan utama limbah ini harus terus menerus dilakukan hingga menemukan hasil yang benar-benar ramah lingkungan dan tetap berestetika tinggi. Proses penciptaan karya boneka wayang baru dari limbah masih bersifat eksploratif, masih dibutuhkan pemikiran, dan kreativitas untuk menghasilkan boneka wayang baru yang menggunakan konsep tradisi yang dikembangkan dengan tetap mengarah kepada karya wayang boneka yang adiluhung.

Perlu mempublikasikan hasil karya pertunjukan Wayang Golek inovasi dengan memanfaatkan berbagai media yang tersedia dan melibatkan pakar seni yang mampu memberikan sumbang saran tentang pengembangan Wayang Golek, khususnya Wayang Golek Ménak Sentolo.

Hasil yang dicapai pada eksplorasi pembuatan boneka Wayang Golek dari bahan limbah dapat mengurangi bobot antara $30 \%$ sampai dengan $50 \%$ lebih ringan apabila dibandinglkan dengan bobot boneka wayang dari bahan utama kayu. Sedangkan nilai bahannya dapat dikatakan murah karena memanfaatkan barang-barang limbah.

Wayang golek hewan kuda dapat menghasilkan boneka yang tampak besar dua kali lipat dengan tinggi $60 \mathrm{~cm}$ dan panjang $80 \mathrm{~cm}$ hanya berbobot $400 \mathrm{gram}$. Dengan demikian dapat disimpulkan bahwa boneka wayang dari bahan limbah lebih ringan apabila dibandingkan dengan boneka wayang berbahan utama kayu.

Wayang Boneka Ringan ini bukan satusatunya usaha untuk menghidupkan Wayang Golek Ménak Sentolo di Yogyakarta yang kini sudah menjadi pertunjukan wayang langka. Akan tetapi, yang dilakukan oleh penulis hanyalah salah satu usaha untuk memunculkan kembali pertunjukan Wayang Golek Ménak Sentolo dengan nuansa baru, walaupun tidak semuanya merupakan barang baru. Barang lama masih dapat ditampilkan walaupun dengan wujud baru.

Kiranya juga perlu dipikirkan untuk mengembangkan Wayang Golek Ménak Sentolo dengan mempertimbangkan biaya yang semurahmurahnya, serta mampu menarik penonton, sehingga menghasilkan karya yang saérah (saé tur mirah), tidak mahal akan tetapi tetap bagus dan ramah lingkungan.

Perlu digagas strategi konservasi dan preservasi terhadap Wayang Golek Ménak Sentolo melalui perancangan model pertunjukan Wayang Golek yang disajikan dengan bentuk pertunjukan Wayang Golek inovasi yang tetap berpijak pada Wayang Golek Ménak Sentolo sebagai apresiasi masyarakat.

Tidak kalah pentingnya juga perlu dipertimbangkan untuk pembuatan Wayang Golek berbahan utama kayu, di samping pohon pule, waru, dondong jaran, dan jaranan yang lambat laun punah karena tidak dibudidayakan, pertimbangan peresapan air tanah juga perlu dipertimbangkan, karena semakin banyak menebang kayu akan terjadi erosi. Sedangkan di lain hal, pemanfatan limbah perlu diusahakan agar mampu mengurangi limbah sampah yang akan bermasalah pada kebersihan lingkungan

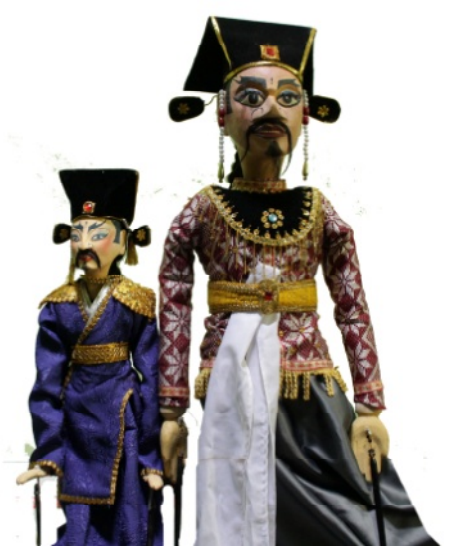

Gambar 11. Kiri wayang boneka dengan teknik gapit, kanan wayang boneka dengan teknik tangan

(Dokumentasi foto; Trisno Santoso.2018)

\section{KEPUSTAKAAN}

Hendrawan, Aldi. 2017. Pergeseran Teknik dan Material Marbling Pada Tektil Sebagai Konsekuensi dari Perkembangan dan Inovasi Panggung, 27, (27) 4-5

Murdiyati, Y. 1984. Widiprayitna Tokoh dan Dalang Wayang Golek Gaya Yogyakarta, 19601984 (Penelitian), ASTI, Yogyakarta.

Riyanto, B. M.S. 2018. Perkembangan Wayang Alternatif di Bawah Hegemoni Wayang Kulit Purwa. Panggung, 26 (2), 5-7 


\section{GELAR Jumal saib butsag}

Santoso, Trisno. 2016. Wayang Boneka Wong Agung Jayengrana, 1980-2016. (Desertasi), Institut Seni Indonesia (ISI) Surakarta.

Satata, Soediro. 2012. Analisis Drama \& Teater. Surakarta: UNU Press.

Soetarno. 1990. Wayang Golek Jawa, 1976-1990). (Penelitian), Sekolah Tinggi Seni Indonesia (STSI) Surakarta.
Sukistono, Dewanto. 2013. Wayang Golek Menak Yogyakarta Bentuk Bentuk dan Struktur Pertunjukannya, 1975-2013. (Desertasi) Institut Seni Indonesia (ISI) Yogyakarta.

Sunardi, N. S. K. 2016. Pertunjukan Wayang Babad Nusantara Wahana Pengajaran Nilai Kebangsaan Bagi Generasi Muda Panggung, 26 (2), 196. 